\title{
QUANTIFICAÇÃO DA ILHA DE CALOR DE CURITIBA CONSIDERANDO ASPECTOS DE ESTABILIDADE ATMOSFÉRICA
}

\author{
EDUARDO KRÜGER ${ }^{1}$, FRANCINE ROSSI ${ }^{2}$
}

\author{
${ }^{1}$ Universidade Tecnológica Federal do Paraná (UTFPR), Departamento de Construção Civil, Campus \\ Curitiba, Sede Ecoville, Curitiba, PR, Brasil
}

${ }^{2}$ Universidade Federal do Paraná, Centro Politécnico, Departamento de Expressão Gráfica, Curitiba, PR, Brasil

ekruger@utfpr.edu.br, rossi@ufpr.br

Recebido Novembro de 2013 - Aceito Abril de 2015

\begin{abstract}
RESUMO
A relação entre crescimento urbano e o surgimento de ilhas de calor urbanas, ou seja, diferenças climáticas entre a área urbana e as áreas rurais no entorno, é demonstrada por diversos autores e em diferentes regiões climáticas. Em Curitiba, a população saltou de aproximadamente 600.000 habitantes para um milhão e meio em três décadas. O objetivo do presente trabalho é propor uma metodologia de análise da ilha de calor urbana de Curitiba $\left(25^{\circ} 25^{\prime} 40^{\prime \prime} \mathrm{S}, 49^{\circ} 16^{\prime} 23^{\prime \prime} \mathrm{W}, 934 \mathrm{~m}\right.$ acima do nível do mar). A cidade está localizada em região de clima subtropical de altitude; o monitoramento climático foi conduzido segundo uma série anual, entre dezembro de 2011 e fevereiro de 2013, utilizando um par de estações meteorológicas dentro e fora (perifericamente) da mancha urbana de Curitiba. De modo a minimizar possíveis influências atmosféricas na análise, foi feita a classificação dos dias de medição por classes de estabilidade atmosférica segundo o método de Pasquill-Gifford-Turner (PGT), procedendo-se à análise para dias com maior estabilidade atmosférica. Como complemento à análise, adota-se um modelo de conforto desenvolvido para Curitiba a partir de uma extensa pesquisa de sensação e percepção térmicas em espaços abertos, de modo a verificar o efeito integrado das diversas variáveis climáticas em termos de percentuais de horas em frio, conforto e calor e suas variações dentro e fora da área urbana. Em Curitiba, a ilha de calor urbana pode ser benéfica durante o inverno, porém trazendo consequências em termos de excesso de calor em ambientes internos no verão.

Palavras-chave: ilha de calor urbana, crescimento urbano, método de Pasquill-Gifford-Turner.
\end{abstract}

\section{ABSTRACT:QUANTIFYING CURITIBA'S URBAN HEAT ISLAND UNDER CONSIDERATION} OF ATMOSPHERIC STABILITY ASPECTS

The relationship between urban growth and the formation of urban heat islands, i.e. climatic differences between the urban area and adjacent rural areas, is discussed by several authors under various climatic regions. In Curitiba, population rose from approximately 600,000 inhabitants to 1,5 Million within three decades. The purpose of this paper is to present a methodology used for analyzing the urban heat island of Curitiba $\left(25^{\circ} 25^{\prime} 40^{\prime}\right.$ 'S , 49 ${ }^{\circ} 16^{\prime} 23^{\prime \prime} \mathrm{W}, 934 \mathrm{~m}$ a.s.l), under consideration of atmospheric stability aspects. The city is located within a region of subtropical climate in elevation; yearlong climate monitoring was carried out between December 2011 and February 2013 using a pair of weather stations in and outside (peripheral) the urban area. As a measure of minimizing bias from varying atmospheric conditions over the entire monitoring period, atmospheric stability classes were applied to the data set according to the Pasquill-Gifford-Turner (PGT) scheme. The analysis was then carried out for days with higher atmospheric stability. An additional element in the analysis is the adoption of a comfort model developed for Curitiba, from an extensive outdoor comfort field survey. The results reflect the integrated influence of the meteorological variables in terms of percentages of cold, comfortable and hot hours and variations in and outside the urban area. For Curitiba, the urban heat island can be beneficial during the colder period of the year although situations may arise in summer and across more populated urban areas, where excess heat would bring thermal discomfort indoors.

Keywords: urban heat island, urban growth, Pasquill-Gifford-Turner scheme. 


\section{INTRODUÇÃO}

A relação entre urbanização e surgimento de ilhas de calor é apontada na literatura como consequência natural do processo de crescimento urbano. Oke (1978) apresenta em sua obra seminal "Boundary Layer Climates" uma relação entre tamanho de cidades diversas em termos populacionais e a intensidade da ilha de calor. Atualmente, as taxas de urbanização apresentam uma tendência crescente em diversos locais do planeta, sendo cerca de 3,5 vezes mais elevadas em regiões em desenvolvimento, comparativamente às regiões desenvolvidas, atingindo uma diferença 5 vezes mais alta entre ambas as regiões na metade do século XXI (United Nations, Department of Economic and Social Affairs, 2012). Considerando o fato de que grande parte das regiões em desenvolvimento se situa em regiões tropicais, a definição de políticas de planejamento urbano que norteiem um crescimento ordenado do ponto de vista microclimático assume grande importância.

No Brasil, a maior parte das cidades cresceu de forma desordenada, agravando assim a deterioração do ambiente. A intensidade da ilha de calor em São Paulo, por exemplo, quantificada por Lombardo na década de 1980, aponta diferenças de $10^{\circ} \mathrm{C}$ entre áreas urbanas e rurais, particularmente em áreas mais poluídas e adensadas na cidade (Lombardo, 1985).

Como uma das poucas exceções, Curitiba contou com um processo permanente e institucionalizado de planejamento urbano, desde 1943, com o "Plano Agache”. Porém, a mecanização do campo na década de 1970, associada à criação da Cidade Industrial de Curitiba - CIC, atraiu grande número de imigrantes em busca de oportunidades de trabalho. O movimento migratório foi realimentado na década de 1990, impulsionado pelo eficiente citymarketing municipal e pela vinda de empresas montadoras de automóveis, induzindo a um crescimento acelerado de Curitiba e dos municípios circunvizinhos. O modelo de planejamento urbano que vinha sendo realizado até então, mostrou-se limitado em relação aos inúmeros problemas sócio-ambientais evidenciados: ocupações irregulares em áreas de mananciais hídricos da região, inundações cada vez mais frequentes, desconforto ambiental e poluição atmosférica agravada pelo desenho urbano e pela organização espacial da região intensamente urbanizada, dentre outros efeitos (Dumke, 2007).

O crescimento acelerado aliado ao planejamento urbano extensivo e à particularidade climática (maior desconforto por frio durante o ano) torna relevante o questionamento do modelo de planejamento urbano de Curitiba, que, mesmo tido como exemplar, não considera o impacto das ações urbanas no clima local.

Lemos (2011) corrobora a visão apresentada acima e apresenta, a partir de análise termográfica de superfície, o efeito da espacialidade na intensidade da ilha de calor (período diurno, sobre imagem de satélite em situação de inverno, no período da manhã). Os resultados obtidos comprovaram haver uma relação direta entre grau de urbanização e incremento da temperatura local.

Desta forma, do desenvolvimento urbano resultou uma cidade na qual se destacam não só as áreas verdes, o sistema viário, a variação da localização das indústrias ao longo do tempo, mas também a diversidade sócio-espacial das habitações, entre outros problemas sócio-ambientais. Porém, sua configuração espacial se caracteriza hoje principalmente pela maciça verticalização ao longo das Vias Estruturais, que transformou de forma radical o sistema urbano polinucleado préexistente acarretando em um importante impacto na paisagem urbana e nos aspectos do conforto ambiental. Margeando os Eixos Estruturais criados para direcionar o crescimento da cidade e o fluxo de veículos, o zoneamento proporcionou a construção de edifícios em altura que formam cânions urbanos alterando os campos térmicos (Minella et al., 2011), a iluminação natural (Suga e Krüger, 2009), a ventilação e a qualidade do ar (Minella et al., 2011).

Procura-se neste artigo apresentar uma metodologia de quantificação dos efeitos gerados pela urbanização existente sobre o microclima em termos da intensidade da ilha de calor urbana. Para atingir tal objetivo, levam-se em conta fatores de estabilidade atmosférica de modo a se obter uma mais nítida quantificação da ilha de calor. Como procedimento complementar, adicionou-se uma análise dos efeitos gerados a partir do microclima urbano na sensação térmica ao nível do pedestre.

\section{MATERIAIS E MÉTODO}

Partes integrantes do presente estudo de ilha de calor são as seguintes:

1) Monitoramento microclimático durante uma série anual (abrangendo diferentes estações do ano e diversos tipos de tempo);

2) Classificação do período de monitoramento por classes de estabilidade atmosférica (ou Dias-Tipo definidos a partir da amostra);

3) Comparação das intensidades verificadas por cada período (estações do ano, períodos específicos ou Dias-Tipo) com identificação dos maiores valores e frequência de ocorrência;

4) Análise dos efeitos de cada período (estações do ano, períodos específicos ou Dias-Tipo) na sensação térmica predita ao nível do pedestre / consequências nos níveis de conforto/ desconforto em espaços abertos;

5) Avaliação da representatividade dos períodos de máxima intensidade nas séries históricas. 


\subsection{Clima local}

Situada em uma latitude de $25^{\circ} 25^{\prime} 40^{\prime \prime} \mathrm{S}$, longitude $49^{\circ} 16^{\prime} 23^{\prime \prime} \mathrm{W}$ e altitude aproximada de $934 \mathrm{~m}$ acima do nível do mar, Curitiba e sua Região Metropolitana apresentam tipo climático predominantemente mesotérmico com verão fresco (Cfb), segundo a classificação de Koeppen, ou clima subtropical de altitude. A área urbana caracteriza um clima urbano-regional particular, pois forma uma ilha de frescor em relação às cidades vizinhas, devido ao efeito do relevo associado à dinâmica atmosférica (Dumke, 2007). A formação de tipos de tempo quente na área deve-se a duas das três massas de ar dominantes e de origem tropical (MTa - Massa Tropical Atlântica e MTc Massa Tropical Continental, e esporadicamente a MEc - Massa Equatorial Continental), que reforçam o efeito da latitude local. As frequentes baixas temperaturas regionais e locais ocorrem devido à massa extratropical (Mpa - Massa Polar Atlântica), que se associa ao efeito da altitude.

Embora a temperatura média das máximas esteja em torno dos $20^{\circ} \mathrm{C}$ no verão, as temperaturas absolutas podem aproximar-se dos $40^{\circ} \mathrm{C}$. No inverno, as temperaturas atingem inúmeras vezes valores negativos, principalmente ao Sul da região metropolitana, situando-se a média das temperaturas mínimas em torno de $13^{\circ} \mathrm{C}$. A área apresenta-se com alta umidade (com umidade absoluta variando entre 4-18 g/ $\mathrm{kg}$ ) o ano todo, com pluviosidade geralmente superior a $1300 \mathrm{~mm}$ anuais. Destaca-se ainda a variabilidade diária e anual do clima (Mendonça e Dubreuil, 2005). Amplitudes térmicas diárias podem variar entre 0,5 e $25,7^{\circ} \mathrm{C}$.

\subsection{Monitoramento térmico para quantificação da ilha de calor de Curitiba}

Como forma de verificar os efeitos do aglomerado urbano no clima local, realizou-se inicialmente uma série de verificações a fim de comprovar a existência de uma ilha de calor na cidade (Krüger e Dumke, 2007), a partir de dados meteorológicos do ano de 2004 fornecidos pelo Sistema Meteorológico do Paraná (SIMEPAR), órgão responsável pelo monitoramento climático do Estado do Paraná, para duas localidades: Pinhais e Curitiba. Os dados foram coletados em base horária simultaneamente em duas estações meteorológicas padrão $\mathrm{WMO}^{1}$ : em Curitiba, no Centro Politécnico da Universidade Federal do Paraná,

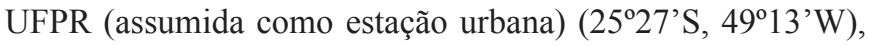
e no município de Pinhais, em área periurbana (estação rural) $\left(25^{\circ} 25^{\prime} \mathrm{S}, 49^{\circ} 8^{\prime} \mathrm{W}\right)$, compreendendo pressão atmosférica [hPa], radiação solar $\left[\mathrm{W} / \mathrm{m}^{2}\right]$, temperatura do $\operatorname{ar}\left[{ }^{\circ} \mathrm{C}\right]$ e umidade relativa [\%], precipitação $[\mathrm{mm}]$, velocidade e direção do vento $[\mathrm{m} / \mathrm{s}$;

\footnotetext{
${ }^{1}$ World Meteorological Organization - Organização Mundial de
} Meteorologia. graus], velocidade e direção de rajada [m/s; graus]. O ano de 2004 foi adotado no estudo por ser o único ano até então a conter dados simultâneos e sem falhas nas duas estações de análise. Com base nesses dados, foi feita uma série de verificações e análises quanto a diferenças encontradas entre temperatura do ar local dentro e fora de Curitiba, ou seja, relativamente a diferenças entre a estação rural e a urbana em Curitiba, para se compreender o comportamento da ilha de calor local. Tais verificações foram feitas sobre generalizações propostas por diversos autores, apresentadas por Arnfield (2003), em sua revisão de estudos em clima urbano realizados entre 1980 e 2000, quais sejam:

- a intensidade da ilha de calor urbana decresce com o aumento da velocidade de vento;

- a intensidade da ilha de calor urbana decresce com o aumento da nebulosidade;

- a intensidade da ilha de calor urbana é mais intensa no período noturno;

- a intensidade da ilha de calor urbana tende a se desenvolver com mais frequência no verão ou nos períodos mais quentes do ano;

- a ilha de calor urbana pode desaparecer durante o dia ou a cidade pode ser mais fria que a área rural;

- taxas de aquecimento e resfriamento são maiores em áreas rurais que na cidade.

De um modo geral, os resultados iniciais encontrados mostraram haver tendências no comportamento das variáveis medidas em ambas as estações que se adequaram às assertivas citadas acima (Krüger e Dumke, 2007).

O presente estudo utiliza dados coletados em duas diferentes regiões da cidade: na referida estação meteorológica do SIMEPAR, no Centro Politécnico da UFPR (assumida como estação urbana) e na região denominada Ecoville, no Campus Ecoville da Universidade Tecnológica Federal do Paraná, UTFPR (estação periurbana, assumida como "peri-urbana" ou "rural"). A posição geográfica das duas estações mostra a localização mais central da primeira e a situação periférica da segunda (Figura 1). A distância aproximada entre as duas estações é de $12 \mathrm{~km}$.

A "Estação Ecoville" foi implementada em dezembro de 2011, sendo da marca HOBO, modelo H21-00. A estação estava equipada com um sensor de temperatura e umidade (S-THB-M002); piranômetro de silício (S-LIB-M003) e sensor de direção e velocidade do vento (S-WCA-M003). A "Estação SIMEPAR" foi implementada em 1997 desde quando monitora dados horários continuamente. Os equipamentos adotados pelo SIMEPAR nas estações meteorológicas automáticas são: barômetro Sutrom Accubar, Modelo 5600-0120 altura do sensor de 1,60 m, piranômetro LI-COR Radiation Sensor e LI-200 SA Pyranometer Sensor, com detector fotovoltaico de 
alta estabilidade, altura do sensor de 2,00 m, Termohigrômetro Sutron Relative Humidity and Air Temperature Probe, Modelo 5600-0313-1 com altura do sensor de 1,70 m e Anemômetro Young Meteorological Instruments, Modelo 05103, monitor de vento com altura do sensor de $10,00 \mathrm{~m}$.

Em termos de localização geográfica e características do entorno, a Estação Ecoville está localizada sobre a cobertura de um dos prédios edificados para a UTFPR, sobre uma laje de concreto, desobstruída de edificações. Não há fontes de calor antropogênico significativas no entorno. Observa-se que não foi cogitada nenhuma correção das variáveis climáticas monitoradas em função da altura das medições (cerca de $15 \mathrm{~m}$ do nível do terreno), sendo esta uma limitação do estudo.

A Estação SIMEPAR situa-se no Centro Politécnico da Universidade Federal do Paraná, em área urbanizada no município pólo da Região Metropolitana de Curitiba. A estação encontra-se instalada em uma superfície gramada na entrada do campus universitário, parte mais elevada do terreno. As poucas obstruções à radiação solar direta e difusa são as pequenas construções próximas à estação, além de poucas árvores esparsas localizadas principalmente no lado sul da estação. Os demais edifícios e conjuntos de árvores de porte do entorno possuem a proporção adequada entre sua altura e distância da estação meteorológica, de forma a não configurarem obstruções. A BR-277, que se encontra a uma distância aproximada de 50m da estação, constitui importante fonte de calor antropogênico. Além desta via de intenso tráfego, que é asfaltada, outras ruas de menor movimento e internas ao campus cercam a estação a distâncias sempre maiores que $20 \mathrm{~m}$, revestidas de paralelepípedos de granito, alterando desta forma a refletividade e absortância da grama verde clara predominante na área.
O período de monitoramento das variáveis climáticas em cada local compreende 16/12/2011 a 19/02/2013, com algumas falhas nesse intervalo devido à perda de dados, conforme a Tabela 1. A mesma tabela mostra a definição adotada para as estações do ano.

\subsubsection{Definição dos períodos de análise}

A análise da ilha de calor foi realizada a partir das diferenças térmicas encontradas entre ambas as estações, para o período completo, para condições de verão e inverno e para um conjunto de dias classificados segundo condições atmosféricas observadas. Tal classificação por classe de estabilidade atmosférica foi realizada a partir do método denominado PGT. Pasquill e Gifford (Pasquill, 1961) propuseram inicialmente uma classificação de estabilidade atmosférica segundo seis classes, sendo posteriormente adicionada a classe $\mathrm{G}$, que representa condições noturnas estáveis de baixa velocidade do ar (Mohan

Tabela 1 - Conjunto de dados analisados, por períodos monitorados.

\begin{tabular}{|c|c|c|}
\hline Período & Datas/intervalos & N (dias) \\
\hline & $16 / 12 / 2011$ a $23 / 01 / 2012$ & \\
& $26 / 01 / 2012$ a $19 / 02 / 2012$ & \multirow{3}{*}{ Período completo } \\
& $21 / 02 / 2012$ a $24 / 05 / 2012$ & 387 \\
& $30 / 06 / 2012$ a $15 / 02 / 2013$ & \\
& $17 / 02 / 2013$ a $19 / 02 / 2013$ & \\
\hline & $21 / 12 / 2011$ a $23 / 01 / 2012$ & \\
& $26 / 01 / 2012$ a $19 / 02 / 2012$ & \\
Períodos de verão & $21 / 02 / 2012$ a $20 / 03 / 2012$ & \multirow{2}{*}{147} \\
& $21 / 12 / 2012$ a $15 / 02 / 2013$ & \\
& $17 / 02 / 2013$ a $19 / 02 / 2013$ & \\
\hline Período de inverno & $30 / 06 / 2012$ a $22 / 09 / 2012$ & 83 \\
\hline
\end{tabular}

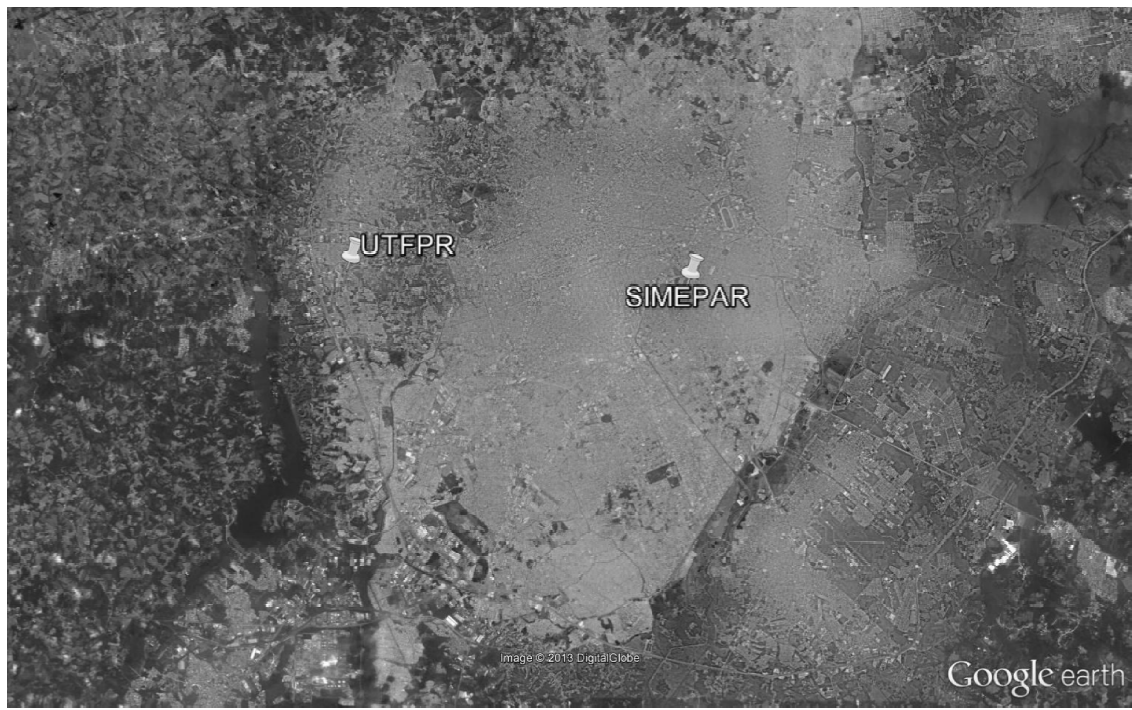

Figura 1 - Localização das estações analisadas.

Fonte: Google Earth (imagem de satélite em 07/07/2009) 
Tabela 2 - Classes de estabilidade atmosférica segundo o método Pasquill-Gifford-Turner (PGT).

\begin{tabular}{|c|c|c|c|c|c|c|c|}
\hline $\begin{array}{c}\text { Velocidade } \\
\text { do vento } \\
(\mathbf{m} / \mathbf{s})\end{array}$ & \multicolumn{4}{|c|}{ Período Diurno } & \multicolumn{3}{c|}{$\begin{array}{c}\text { Período Noturno } \\
\text { Nebulosidade } \\
\text { (oitavas) }\end{array}$} \\
\cline { 2 - 8 } & $\begin{array}{c}\text { Alta } \\
(>\mathbf{6 0 0})\end{array}$ & $\begin{array}{c}\text { Moderada } \\
(\mathbf{3 0 0 - 6 0 0 )}\end{array}$ & $\begin{array}{c}\text { Leve } \\
(<\mathbf{3 0 0})\end{array}$ & Nublado & $\mathbf{0 - 3}$ & $\mathbf{4 - 7}$ & $\mathbf{8}$ \\
\hline$\leq 2,0$ & $\mathrm{~A}$ & $\mathrm{~A}-\mathrm{B}$ & $\mathrm{B}$ & $\mathrm{C}$ & $\mathrm{G}-\mathrm{F}$ & $\mathrm{F}$ & $\mathrm{D}$ \\
\hline $2,0-3,0$ & $\mathrm{~A}-\mathrm{B}$ & $\mathrm{B}$ & $\mathrm{C}$ & $\mathrm{C}$ & $\mathrm{F}$ & $\mathrm{E}$ & $\mathrm{D}$ \\
\hline $3,0-5,0$ & $\mathrm{~B}$ & $\mathrm{~B}-\mathrm{C}$ & $\mathrm{C}$ & $\mathrm{C}$ & $\mathrm{E}$ & $\mathrm{D}$ & $\mathrm{D}$ \\
\hline $5,0-6,0$ & $\mathrm{C}$ & $\mathrm{C}-\mathrm{D}$ & $\mathrm{D}$ & $\mathrm{D}$ & $\mathrm{D}$ & $\mathrm{D}$ & $\mathrm{D}$ \\
\hline$>6,0$ & $\mathrm{C}$ & $\mathrm{D}$ & $\mathrm{D}$ & $\mathrm{D}$ & $\mathrm{D}$ & $\mathrm{D}$ & $\mathrm{D}$ \\
\hline
\end{tabular}

Fonte: adaptado de Mohan e Siddiqui (1998).

e Siddiqui, 1998), quais sejam: A (altamente instável), B (moderadamente instável), C (pouco estável), D (estabilidade neutra), E (moderadamente estável), e F (extremamente estável). Tal classificação foi posteriormente revista por Turner (Turner, 1970), sendo o método então denominado PasquillGifford-Turner (PGT). O método PGT consiste em analisar separadamente períodos diurnos e noturnos, atribuindo a classificação em função da velocidade do vento, irradiância solar (período diurno) e nebulosidade (período noturno), sendo os dois períodos definidos pelos horários de nascer e pôr do sol, porém desconsiderando-se uma hora após o nascer do sol e uma hora antes do pôr do sol. A Tabela 2 mostra os limites propostos pelo método PGT para cada classe atmosférica.

Como o método exige a disponibilidade de dados de nebulosidade, buscou-se uma fonte de dados climáticos que fornecesse tal informação. A Rede de Meteorologia do Comando da Aeronáutica (REDEMET, disponível em http://www. redemet.aer.mil.br) fornece dados meteorológicos sob a forma de relatórios METAR $^{2}$ para uma rede de estações localizada no território brasileiro. A estação utilizada para a coleta de dados de nebulosidade foi a do Aeroporto Afonso Pena, SBCT, localizada ao sudeste de Curitiba. Nas estações da REDEMET, a nebulosidade é obtida pelo método de observação visual, de acordo com os procedimentos FCA 105-3 e MCA 105-2, disponíveis no site da REDEMET. Os códigos METAR (SKC/ $\mathrm{CLR}=$ 'Sky Clear'/'Clear' ou sem nuvens; $\mathrm{NSC}=$ 'No significant cloud'; FEW = 'Few' ou 1-2 oitavas; $\mathrm{SCT}=$ 'Scattered' ou 3-4 oitavas; BKN = 'Broken' ou 5-7 oitavas; OVC = 'Overcast' ou 8 oitavas) foram adaptados de forma a se poder agrupá-los nas três categorias de nebulosidade mostradas na Tabela 2 .

De forma a desconsiderar os períodos de transição entre noite e dia, foram desconsideradas duas horas em torno dos horários de nascer e pôr do sol (uma hora a mais que no método PGT), os quais foram determinados matematicamente segundo dia do ano, declinação magnética e latitude local, conforme Szokolay (1983). Finalmente, na aplicação dos limites da

${ }^{2}$ METeorological Aerodrome Report - Informe meteorológico regular de aeródromo.
Tabela 2, adotou-se a classificação por maior proximidade das variáveis, sendo que os dados de entrada foram: a velocidade média do vento em cada período, a intensidade média de irradiância solar global em plano horizontal no período diurno, medidas na Estação Ecoville e a nebulosidade média no período noturno, disponibilizados pela estação SBCT/REDEMET. A situação de instabilidade atmosférica diurna, pelo método PGT, correspondente a maior insolação e baixa velocidade do ar foi a mais favorável na intensificação da ilha de calor.

\subsection{Análise de graus de conforto/desconforto}

Um estudo utilizando duas estações meteorológicas da mesma marca e modelo que a implantada na Estação Ecoville, porém dotadas adicionalmente de globos de cobre (com diâmetro de $5 \mathrm{~cm}$ e pintados na cor cinza, nos quais foram inseridos sensores de temperatura tipo PT100 para obtenção da temperatura radiante média Trm), envolveu a coleta de dados microclimáticos e de sensação/percepção térmica de usuários dos trechos de pedestre na e em torno da rua XV de Novembro, zona central de Curitiba (Rossi, 2012). Questionários foram preenchidos por transeuntes, em 15 pontos ao longo do trecho das vias de pedestre e durante 15 levantamentos de campo, entre janeiro e agosto de 2009/2010, no período das 10 h00 as 15 h00, tendo sido monitorados 2 pontos em cada dia. Os questionários de conforto aplicados seguem a norma ISO 10551 (International Organization for Standardization, 1995), envolvendo questões relativas à sensação térmica dos transeuntes. No total, foram obtidos 2024 questionários, sendo considerados 1685 válidos, segundo os seguintes critérios: (1) respondentes que declararam residir em Curitiba ou em sua Região Metropolitana por pelo menos 6 meses; (2) respondentes que declararam estar há pelo menos 15 minutos ao ar livre (ASHRAE, 2004); (3) respondentes que não responderam o mesmo valor (positivo ou negativo) na escala de percepção e de preferência térmica.

Três categorias de sensação térmica foram definidas a partir da associação dos votos de percepção e preferência térmica, da seguinte forma: 
Grupo 1: desconforto para o frio (voto de percepção < 0 associado ao voto de preferência $>0$ );

Grupo 2: conforto (percepção $=0$ e preferência $=0$ );

Grupo 3: desconforto para o calor (percepção $>0$ associado à preferência $<0$ ).

A partir dos dados obtidos nos levantamentos de campo, foi desenvolvido um modelo de predição cuja variável dependente é a sensação térmica, agrupada nas três categorias citadas acima (desconforto para o frio, conforto e desconforto para o calor) e cujas variáveis independentes são as variáveis climáticas monitoradas. No modelo final adotado, utilizaram-se apenas variáveis normalmente registradas em estações meteorológicas oficiais, quais sejam: temperatura (Ta) e umidade relativa do ar (UR), velocidade do vento (Va) e radiação solar global em plano horizontal (RS), de modo a tornar o modelo aplicável a análises diversas no campo da biometeorologia (Rossi, 2012).

O modelo preditivo foi desenvolvido a partir da técnica da análise discriminante linear denominada Função Discriminante Linear (FDL). A FDL é uma das técnicas adequadas quando a única variável dependente é categórica, sendo aplicada em casos nos quais a amostra pode ser dividida em grupos, baseados na variável dependente categórica, permitindo a elaboração de uma função matemática. Desta forma, obteve-se $\mathrm{k}=3$ grupos (desconforto para o frio, conforto e desconforto para o calor) e $\mathrm{m}=4$ variáveis independentes (Ta, UR, Va, RS), o que resultou em três funções discriminantes, cada uma com quatro variáveis (Rossi, 2012). O processo de determinação da FDL para os dados de campo e um exemplo de aplicação são apresentados mais detalhadamente em Rossi et al. (2013).

\section{RESULTADOS E DISCUSSÃO}

A análise foi inicialmente realizada para diferentes períodos: a) para o período completo; b) para as diferentes estações do ano (conforme a Tabela 1); e, c) para dias classificados em função de sua estabilidade atmosférica. Para facilitar a análise da ilha de calor, separaram-se os dados em períodos diurno e noturno, definidos a partir dos horários de nascer e pôr do sol, para cada dia de medição. A Tabela 3 mostra resumidamente valores de temperatura ambiente registrada em cada estação (Estação SIMEPAR versus Estação Ecoville), para o período completo de monitoramento e para as diversas estações do ano.

Nota-se a presença de temperaturas mais baixas na Estação Ecoville (rural ou peri-urbana) de forma mais consistente nas mínimas absolutas e nas médias das mínimas de cada período, tendo como consequência uma temperatura média ligeiramente mais baixa que na área central. Já as máximas absolutas e as médias das máximas apresentam tendências mais variadas, com a temperatura na periferia do centro urbano nem sempre inferior à do ponto urbano (caso das ilhas de frescor).

Aplicou-se então para o total de dias monitorados o método PGT, definindo-se diferentes tipos de dias em função de seu padrão atmosférico, conforme a Tabela 4, obtendo-se nove dias-tipo segundo tal classificação. Ordenaram-se os dias segundo o maior grau de estabilidade atmosférica para o período noturno ("G" condições noturnas extremamente estáveis com baixa velocidade do ar; "F" extremamente estável; "E" moderadamente estável; e, "D" estabilidade neutra), conforme a definição clássica de ilha de calor urbana. Nota-se que a predominância é do Dia-Tipo III na série de dados levantada, o que mostra a importância de se atentar para os padrões de estabilidade atmosférica na análise dos dados. Assim, ressalta-se a relevância da análise da estabilidade atmosférica para dados de campo coletados em estação urbana/rural para se poder compreender melhor os fatores responsáveis pela ocorrência da ilha de calor urbana.

A tabela seguinte (Tabela 5) mostra a intensidade máxima da ilha de calor (noturna) ( $\Delta \mathrm{Tu}-\mathrm{r}(\max )$ ), a média das intensidades diárias e as diferenças médias de temperatura entre as duas estações, para cada período de análise. Os dados mostram que a maior diferença registrada entre as temperaturas

Tabela 3 - Valores extremos (abs) e médios (méd) de Temperatura do ar $\left({ }^{\circ} \mathrm{C}\right)$ registrada nas estações SIMEPAR e Ecoville.

\begin{tabular}{|l|c|c|c|c|c|}
\hline \multicolumn{1}{|c|}{ Situação } & Tmin (abs) & Tmax (abs) & $\begin{array}{c}\text { Tmin } \\
(\mathbf{m e ́ d})\end{array}$ & T (méd) & $\begin{array}{c}\text { Tmax } \\
(\mathbf{m e ́ d})\end{array}$ \\
\hline Verão (Ecoville) & 12,2 & 32,4 & 16,7 & 20,4 & 25,7 \\
\hline Inverno (Ecoville) & 4,0 & 30,2 & 11,2 & 15,7 & 21,1 \\
\hline Primavera (Ecoville) & 2,7 & 34,3 & 15,1 & 19,2 & 24,8 \\
\hline Outono (Ecoville) & 4,5 & 28,5 & 13,4 & 16,7 & 21,1 \\
\hline Ano todo (Ecoville) & 2,7 & 34,3 & 14,6 & 18,5 & 23,7 \\
\hline Verão (SIMEPAR) & 11,7 & 32,2 & 17,2 & 20,7 & 25,6 \\
\hline Inverno (SIMEPAR) & 4,4 & 31,4 & 11,1 & 15,8 & 21,6 \\
\hline Primavera (SIMEPAR) & 3,4 & 33,8 & 15,4 & 19,4 & 24,6 \\
\hline Outono (SIMEPAR) & 5,1 & 29,6 & 13,7 & 17,1 & 21,6 \\
\hline Ano todo (SIMEPAR) & 3,4 & 33,8 & 14,9 & 18,7 & 23,8 \\
\hline
\end{tabular}


Tabela 4 - Classificação dos dias pelo procedimento PGT.

\begin{tabular}{|c|c|c|c|}
\hline \multirow{2}{*}{$\begin{array}{c}\text { Tipo de } \\
\text { dia }\end{array}$} & \multicolumn{2}{|c|}{$\begin{array}{c}\text { Classe de estabilidade atmosférica } \\
\text { segundo PGT }\end{array}$} & \multirow{2}{*}{ Quantidade de dias (N) } \\
\cline { 2 - 3 } & (período diurno) & $\begin{array}{c}\text { (período } \\
\text { noturno) }\end{array}$ & \\
\hline I & B & G & 14 \\
\hline II & C & F & 34 \\
\hline III & B & F & 118 \\
\hline IV & A & F & 41 \\
\hline V & C & E & 33 \\
\hline VI & B & E & 78 \\
\hline VII & A & E & 11 \\
\hline VIII & C & D & 24 \\
\hline IX & B & D & 26 \\
\hline
\end{tabular}

Tabela 5 - Intensidade da ilha de calor $(\Delta \operatorname{Tu}-\mathrm{r}(\max ))$ e diferenças médias de temperatura, para diferentes períodos e condições atmosféricas

\begin{tabular}{|l|c|c|c|}
\hline & $\begin{array}{c}\text { Intensidade da } \\
\text { ilha de calor } \\
\left(\Delta \mathbf{T}_{\mathbf{u}-\mathbf{r}(\mathbf{m a x})}\right) \\
\text { máximo absoluto }\end{array}$ & $\begin{array}{c}\text { Intensidade da } \\
\text { ilha de calor } \\
\left(\Delta \mathbf{T}_{\mathbf{u}-\mathbf{r}(\mathbf{m a x})}\right)-\mathbf{m e ́ d i a} \\
\text { para o período }\end{array}$ & $\begin{array}{c}\text { Diferença média } \\
\text { horária } \\
\left(\Delta \mathbf{T}_{\mathbf{u}-\mathbf{r}(\mathbf{m e d})}\right)\end{array}$ \\
\hline $\begin{array}{l}\text { Período completo } \\
\text { (diurno) }\end{array}$ & 11,5 & - & $-0,3$ \\
\hline $\begin{array}{l}\text { Período completo } \\
\text { (noturno) }\end{array}$ & 5,3 & 1,2 & 0,5 \\
\hline Verão & 5,3 & 1,2 & 0,6 \\
\hline Inverno & 2,7 & 1,2 & 0,3 \\
\hline$D I A-T I P O I$ & 3,1 & 1,5 & 0,5 \\
\hline$D I A-T I P O I I$ & 3,7 & 1,4 & 0,5 \\
\hline DIA-TIPO III & $\mathbf{5 , 3}$ & $\mathbf{1 , 4}$ & $\mathbf{0 , 6}$ \\
\hline$D I A-T I P O I V$ & 2,5 & 1,1 & 0,5 \\
\hline$D I A-T I P O V$ & 5,1 & 1,2 & 0,5 \\
\hline$D I A-T I P O V I$ & 2,7 & 1,1 & 0,5 \\
\hline$D I A-T I P O V I I$ & 1,5 & 1,0 & 0,5 \\
\hline$D I A-T I P O$ VIII & 2,2 & 1,1 & 0,6 \\
\hline$D I A-T I P O I X$ & 2,7 & 1,0 & 0,6 \\
\hline
\end{tabular}

do ar medidas na Estação SIMEPAR e na Estação Ecoville ocorre no período diurno, em razão de ganhos radiantes diferenciados nas estações durante o dia. O padrão, porém, não se mantém para as diferenças médias, que mostram a existência de uma pequena ilha de frescor na área urbana. Quanto aos dados noturnos, período durante o qual os ganhos solares não estão presentes, mas apenas o calor armazenado nas superfícies do entorno e as trocas convectivas, nota-se maior consistência nos dados. A máxima intensidade da ilha de calor ocorre no período de verão (em 02/02/2013), sendo a média dos dados obtidos de intensidade da ilha de calor mais alta também nessa estação. Tais resultados comprovam a generalização proposta por diversos autores, apresentada por Arnfield (2003), a partir de uma extensa revisão de estudos na área de clima urbano entre 1980 e 2000 na área de clima urbano, de que a intensidade da ilha de calor urbana tende a se desenvolver com mais frequência no verão ou nos períodos mais quentes do ano. A mesma verificação foi comprovada no estudo inicial (Krüger e Dumke, 2007), o qual mostrou que a média das diferenças de temperatura urbano-rural é mais significativa para o período mais quente, tanto para as mínimas, quanto para as máximas diárias.

A Tabela 5 também sugere que a utilização de uma classificação dos dias de monitoramento por grau de estabilidade atmosférica facilita a análise e a identificação da magnitude média da ilha de calor em dias de condições ideais para ocorrência de tal fenômeno. Os dias-tipo I-III apresentaram o maior valor de magnitude média da ilha de calor, enquanto que a máxima intensidade da ilha de calor ocorre sob as condições do Dia-Tipo III. O efeito observado em termos de intensidade média da ilha de calor é mais evidente nos dias-tipo I a III, nos 
quais a classe PGT para o período noturno é G ou F (Tabela 4). A maior intensidade da ilha de calor observada está entre esses três dias-tipo. Como esperado (primeira assertiva mencionada por Arnfield, citada anteriormente), a ilha de calor se intensifica com baixa velocidade do ar no período noturno, justificando a ocorrência de valores mais altos também para o dia-tipo $\mathrm{V}$, o qual inclui a condição E no período noturno.

\subsection{Efeito observado nos graus de conforto/desconforto}

A integração das diversas variáveis microclimáticas em um modelo de conforto, expresso em categorias de sensação térmica (Grupo 1=frio, Grupo 2=conforto e Grupo 3=calor), acrescenta um elemento adicional à análise da ilha de calor, que leva em consideração apenas a temperatura do ar (Krüger et al., 2012). O modelo de predição de sensação térmica, agrupada segundo as três categorias citadas acima (desconforto para o frio, conforto e desconforto para o calor), foi aplicado às variáveis climáticas monitoradas em cada estação. Os mesmos períodos e dias-tipo foram adotados para a análise dos percentuais de horas em cada categoria, sendo apresentadas na Tabela 6 e Figura 2 as diferenças nesses percentuais, para os períodos diurno e noturno, entre a Estação UFPR (urbana) e a Estação Ecoville (rural), em cada situação. Tais resultados tornam-se mais visíveis na comparação direta das variações percentuais de horas em frio, conforto e calor, entre a estação urbana e a rural.

Nota-se que, em todas as situações, a condição urbana apresenta redução do desconforto por frio (Grupo 1) à noite, confirmando a tendência da formação de ilha de calor noturna. Durante o dia, em razão do efeito combinado das diversas variáveis e considerando a presença da radiação solar, não se evidencia uma tendência, sendo o efeito urbano mais aleatório. Ao se observarem os resultados para todos os grupos, comparando-se situação diurna versus noturna, nota-se que a intensidade das variações é maior no período da noite e para o Grupo 1. O Grupo 3 praticamente não aparece no período noturno. A condição verificada anteriormente de maior intensidade da ilha de calor (Dia-Tipo III) não corresponde exatamente àquela com a maior variação percentual em desconforto por frio no período noturno. Contudo, mantém-se os dias-tipo I-III (incluindo-se aqui também o Dia-Tipo IV) como aqueles onde aparece leve aumento do Grupo 3 na área urbana; ou seja, com a ilha de calor, surge o desconforto por calor na integração com outras variáveis (note-se que, nesse contexto, desaparece o efeito da ilha de calor para o dia-tipo V). Uma vez que essas são as condições ideais de observação do efeito da ilha de calor, este seria o comportamento esperado em termos de conforto/desconforto para tal situação, para Curitiba. Na Tabela 7, confirma-se também o efeito mais pronunciado de variações térmicas no período de verão, para áreas urbanas.

Ainda que as variações percentuais em termos de aumento de calor (Grupo3) na área urbana sejam pequenas sob as condições medidas, em condições urbanas de maior adensamento, tal aumento pode trazer situações de overheating interno. Tal situação foi também observada em clima temperado, como em um estudo da ilha de calor de Glasgow, Escócia (Emmanuel e Krüger, 2012), e em Londres, onde foram verificadas reduções de $65-85 \%$ na carga térmica de aquecimento, para localidades mais centrais relativamente a localidades fora da malha urbana, com a demanda por resfriamento aumentando em $32-42 \%$ no centro da cidade (Grimmond, 2011). Um estudo realizado com a base de dados aqui apresentada (Krüger, 2015) mostrou que a realocação de edificações padrão popular da área rural para a área urbana traria consigo um aumento no desconforto interno por calor nessas edificações significativamente maior no verão do que uma redução das condições de frio (vantajosas, para o caso de Curitiba) no inverno. Demonstrou-se que a urbanização local

Tabela 6 - Diferenças em percentuais de horas entre a Estação UFPR (urbana) e a Estação Ecoville (rural) nos três grupos, para cada período.

\begin{tabular}{|c|c|c|c|c|c|c|}
\hline & \multicolumn{2}{|c|}{ Grupo 1: Frio } & \multicolumn{2}{|c|}{ Grupo 2: Conforto } & \multicolumn{2}{|c|}{ Grupo 3: Calor } \\
\hline & dia & noite & dia & noite & dia & noite \\
\hline Período completo & 0 & -7 & 0 & 6 & 0 & 1 \\
\hline Verão & -1 & -12 & 0 & 11 & 0 & 1 \\
\hline Inverno & -1 & -3 & -1 & 1 & 2 & 2 \\
\hline DIA-TIPO I & -4 & -4 & 10 & -1 & -6 & 4 \\
\hline DIA-TIPO II & -8 & -10 & 5 & 9 & 3 & 1 \\
\hline DIA-TIPO III & -1 & -9 & -2 & 8 & 3 & 2 \\
\hline DIA-TIPO IV & 11 & -5 & -2 & 3 & -9 & 2 \\
\hline DIA-TIPO V & -7 & -5 & 6 & 5 & 2 & 0 \\
\hline DIA-TIPO VI & 4 & -8 & -4 & 8 & -1 & 0 \\
\hline DIA-TIPO VII & 5 & -10 & 3 & 10 & -7 & 0 \\
\hline DIA-TIPO VIII & -4 & -3 & 3 & 3 & 0 & 0 \\
\hline DIA-TIPO IX & 2 & -2 & -2 & 2 & 0 & 0 \\
\hline
\end{tabular}




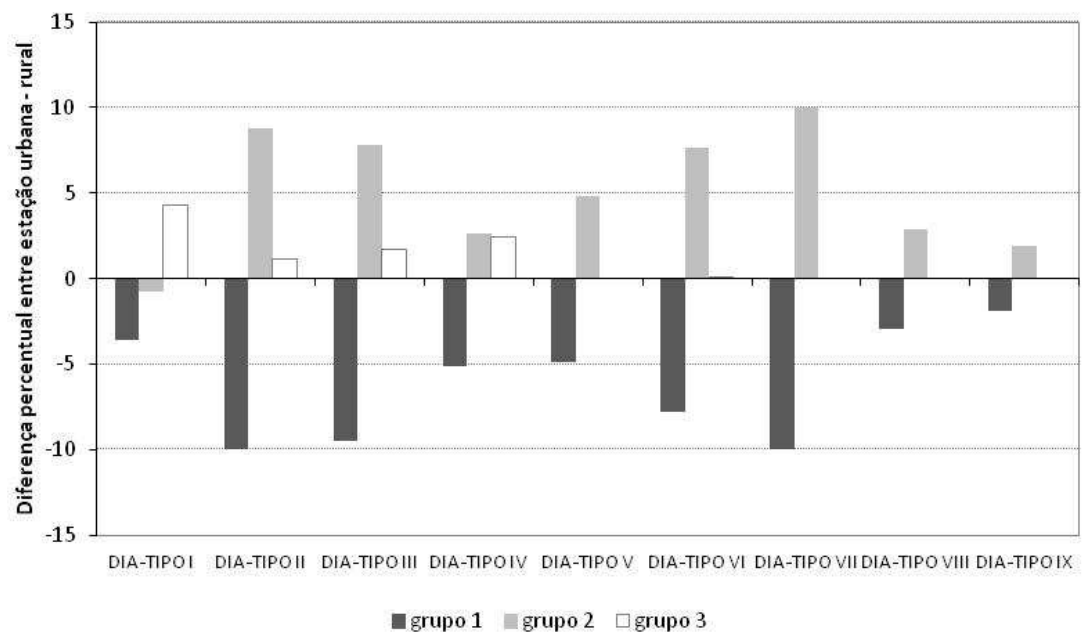

Figura 2 - Efeito da ilha de calor em termos de variações percentuais de horas em frio, conforto e calor, entre a Estação UFPR (urbana) e a Estação Ecoville (rural), para os dias-tipo PGT.

Tabela 7 - Classificação dos dias pelo procedimento PGT para o ano climático de referência TRY

\begin{tabular}{|c|c|c|c|c|}
\hline $\begin{array}{c}\text { Tipo } \\
\text { de } \\
\text { dia }\end{array}$ & \multicolumn{2}{|c|}{$\begin{array}{c}\text { Classe de estabilidade } \\
\text { atmosférica segundo PGT }\end{array}$} & $\begin{array}{c}\text { Quantidade de dias } \\
\text { (N) }\end{array}$ & $\begin{array}{c}\text { Percentual do ano } \\
\text { climático de } \\
\text { referência \% }\end{array}$ \\
\cline { 2 - 3 } & $\begin{array}{c}\text { (período } \\
\text { diurno) }\end{array}$ & $\begin{array}{c}\text { (período } \\
\text { noturno) }\end{array}$ & & \\
\hline I & C & G & 2 & 0,5 \\
\hline II & B & G & 6 & 1,6 \\
\hline III & D & F & 5 & 1,4 \\
\hline IV & C & F & 12 & 3,3 \\
\hline V & B & F & $\mathbf{6 0}$ & $\mathbf{1 6 , 4}$ \\
\hline VI & A & F & 7 & 1,9 \\
\hline VII & D & E & 10 & 2,7 \\
\hline VIII & C & E & 23 & 6,3 \\
\hline IX & B & E & 26 & 7,1 \\
\hline X & A & E & 4 & 1,1 \\
\hline XI & D & D & 36 & 9,9 \\
\hline XII & C & D & 76 & 20,8 \\
\hline XIII & B & D & 88 & 24,1 \\
\hline XIV & A & D & 10 & 2,7 \\
\hline
\end{tabular}

com seus efeitos de intensificação da ilha de calor pode trazer prejuízos em termos de estresse térmico por excesso de calor no interior de edificações.

\subsection{Tendências de desenvolvimento da ilha de calor local}

Goulart et al. (1998) geraram o ano climático de referência para Curitiba para a década de 1960 a partir de dados compilado de fitas magnéticas com dados meteorológicos do CTA/IAE (Centro Técnico Aeroespacial / Instituto de Aeronáutica e Espaço). As fitas magnéticas continham dados climáticos horários, registrados em aeroportos. Os dados de 10 anos foram tratados de acordo com a metodologia para geração do ano climático de referência - TRY (test reference year) (ASHRAE, 1993) e são compostos das variáveis necessárias para que se possa proceder ao esquema de classificação de estabilidade atmosférica PGT. Ao se comparar as classes PGT do TRY gerado para a década de 1960 com as dos dados monitorados, torna-se possível inferir se houve alguma mudança nos padrões atmosféricos desde então.

A classificação PGT para o TRY de Curitiba resultou em 13 classes de estabilidade atmosférica, conforme a Tabela 7. Em termos de frequência de ocorrência, os dias-tipo XI e XII ${ }^{3}$ são os mais representativos, os quais equivalem aos dias-tipo VIII

${ }^{3}$ Nota: não há necessariamente uma correspondência com os dias-tipo da Tabela 4. 
e IX da Tabela 4. Uma vez que se percebeu que a intensidade da ilha de calor é menor para tais dias, tanto em termos de valor absoluto quanto na média para dias com tal classificação, pode-se inferir que as condições atmosféricas atuais favorecem uma intensificação da ilha de calor de Curitiba. A maior intensidade da ilha de calor foi verificada na série analisada para o Dia-Tipo III, cuja participação percentual no período monitorado foi de cerca de $31 \%$; na série de dados do TRY, a participação das mesmas condições (Dia-Tipo V) é de apenas $16 \%$, somando-se ainda o fato de que todas as classes $\mathrm{G}$ para o período noturno na série do TRY têm frequência ligeiramente inferior à observada na série atual.

Observa-se que o desenvolvimento urbano a partir da década de 1960 (dados base para a obtenção do TRY) se deu especialmente pela verticalização do município-pólo devido ao maior impulso no setor imobiliário e da construção civil. Porém, foi o processo de adensamento acelerado dos municípios periféricos, devido principalmente à instalação de grandes montadoras automobilísticas no final da década de 1990 que caracterizou o crescimento acelerado do Aglomerado Metropolitano no período (Krüger e Dumke, 2007).

\section{CONCLUSÕES}

Sugere-se com o estudo apresentado uma metodologia a ser adotada como procedimento padrão em estudos de ilhas de calor para determinada localidade, relacionando ainda a análise de graus de conforto e desconforto. São partes integrantes dessa metodologia: o monitoramento climático com uso de equipamentos padronizados, devidamente calibrados e com proteção solar adequada; a consideração de uma estação referencial para comparações, fora da malha urbana; a extensão do período de monitoramento, englobando-se períodos de inverno, verão e meia-estação, de modo que se possam selecionar condições de maior estabilidade atmosférica para análise da ilha de calor. Para a análise realizada, foi fundamental a utilização da rede de estações de aeródromos nacionais, REDEMET, com dados de nebulosidade confiáveis para a classificação PGT.

A seleção dos dias de monitoramento pelas condições atmosféricas observadas em cada dia monitorado permitiu identificar a máxima intensidade (ou magnitude) da ilha de calor. Como implicação direta dos resultados encontrados, nota-se que, para Curitiba, a ilha de calor pode, sob condições de extrema estabilidade atmosférica no período noturno e grande irradiâncai solar diurna e considerando-se o fato de se tratar da capital mais fria do país -Goulart et al. 1998, ser benéfica, reduzindo o desconforto por frio. Mostrou-se, no artigo, que essa condição tem uma tendência mais acentuada no ano analisado em relação ao ano climático, mais representativo do clima local. Deve-se ressaltar que as mesmas situações de grande estabilidade térmica noturna (classes $\mathrm{G}$ e $\mathrm{F}$ do esquema PGT, para o período noturno) podem significar um aumento no percentual de horas em situação de calor (Grupo 3). Em situação de verão, um estudo complementar apontou que a ilha de calor local traduziria em edificações padrão popular em um aumento no desconforto interno por calor, sendo este significativamente maior no verão do que a redução das condições de frio no ambiente construído no inverno (Krüger, 2015).

Quanto a tendências de alterações climáticas locais, os resultados sugerem que, ao se comparar as classes PGT do TRY gerado para a década de 1960 com as dos dados coletados, em termos de Dias-Tipo e suas implicações na ilha de calor, as condições atmosféricas atuais favoreceriam uma intensificação da ilha de calor de Curitiba. Considerando as tendências de aquecimento em regiões tropicais, sugeridas por modelos climáticos do tipo "Representative Concentration Pathways", o incremento estimado da temperatura anual nessas regiões situa-se em torno de 4 a $5^{\circ} \mathrm{C}$ ao fim do século (Diffenbaugh e Field, 2013), com consequências para o sobreaquecimento e aumento do estresse térmico por calor externamente, e, de forma mais intensificada, internamente nas edificações.

\section{AGRADECIMENTOS}

Ao Instituto Meteorológico SIMEPAR, pelo fornecimento dos dados.

\section{REFERENCIAS}

ARNFIELD, A. J. Review: two decades of urban climate research: a review of turbulence, exchanges of energy and water, and the urban heat island. International Journal of Climatology, v. 23: p. 1-26, 2003

ASHRAE - AMERICAN SOCIETY OF HEATING, REFRIGERATING AND AIR-CONDITIONING ENGINEERS. Handbook of Fundamentals. Atlanta: ASHRAE. Cap. 24. p. 24.1-24.23, 1993.

ASHRAE. Standard 55 - Thermal environmental conditions for human occupancy. Atlanta, ASHRAE, 2004.

DIFFENBAUGH, N.S.; FIELD, C.B. Changes in Ecologically Critical Terrestrial Climate Conditions. Science, v. 341: p. 486-492, 2013.

DUMKE, E. Clima urbano/conforto térmico e condições de vida na cidade - Uma perspectiva a partir do Aglomerado Urbano da Região Metropolitana de Curitiba (AU-RMC). Tese (Doutorado em Meio Ambiente e Desenvolvimento) Universidade Federal do Paraná, Paraná, 2007.

EMMANUEL, R.; KRÜGER, E.L. Urban heat island and its impact on climate change resilience in a shrinking city: The 
case of Glasgow, UK. Building and Environment, v. 53: p. 137-149, 2012.

GOULART, S.; LAMBERTS, R.; FIRMINO, S. Dados climáticos para projeto e avaliação energética de edificações para 14 cidades brasileiras. Florianópolis: PROCEL/Núcleo de Pesquisa em Construção; UFSC, 1998.

GRIMMOND, C.S.B. London's urban climate: a historical and contemporary perspective. ESRC City weathers: meteorology and urban design 1950-2010, 2011, University of Manchester, Reino Unido (keynote).

IN TERNATIONAL ORGANIZATION FOR STANDARDIZATION. ISO 10551: ergonomics of the thermal environments: assessment of the influence of the thermal environment using subjective judgment scales. Genebra, 1995.

KRÜGER, E.; DRACH, P.; EMMANUEL, R.; CORBELLA, O. Urban heat island and differences in outdoor comfort levels in Glasgow, UK. Theoretical and Applied Climatology, v. 112: p. 127-141, 2012.

KRÜGER, E.; DUMKE, E.M.S. Estudo bioclimático sobre o planejamento urbano de Curitiba. In: IX Encontro Nacional e V Encontro Latino-Americano de Conforto no Ambiente Construído, 2007, Ouro Preto. Anais do IX ENCAC. Belo Horizonte: Universidade Federal de Minas Gerais, 2007.

KRÜGER, E. Urban heat island and indoor comfort effects in social housing dwellings. Landscape and Urban Planning, v. 134; p. 147-156, 2015.

LEMOS, J.S. Espacialização da Ilha de Calor do Aglomerado Urbano da Região metropolitana de Curitiba (AU-RMC) em agosto de 2006 a partir da termografia de superfície. Anais do XV Simpósio Brasileiro de Sensoriamento Remoto-SBSR. São José dos Campos: INPE/SELPER, 2011.

LOMBARDO, M.A. Ilha de Calor nas Metrópoles: o exemplo de São Paulo. São Paulo: Ed. Hucitec, 1985.
MENDONÇA, F.; DUBREUIL V.R. Termografia de Superfície e Temperatura do Ar na RMC (Região Metropolitana de Curitiba/PR). RA'E GA, Curitiba, v. 9, p. 25-35, 2005.

MINELLA, F.O. ; RASIA, F. ; KRÜGER, E.L. Impactos microclimáticos do desenho urbano: estudos realizados em Curitiba. Ra'e ga (UFPR), v. 21: p. 298-338, 2011.

MOHAN, M.; SIDDIQUI, T.A. Analysis of various schemes for the estimation of atmospheric stability classification. Atmospheric Environment, v. 32, n. 21: p. 3775-3781, 1998.

OKE, T. R. Boundary Layer Climates. London, Methuen \& Co., 1978.

PASQUILL, F. The estimation of the dispersion of wind borne materials. Meteorological Magazine, v. 90, n. 1063: p. 3349, 1961.

ROSSI. F. Proposição de metodologia e de modelo preditivo para avaliação da sensação térmica em espaços abertos em Curitiba. 2012. Tese (Doutorado em Tecnologia e Sociedade) - Universidade Tecnológica Federal do Paraná.

ROSSI, F. ; KRÜGER, E.L. ; GUIMARÃES, I. A. Modelo preditivo de sensação térmica em espaços abertos em Curitiba, PR. RA'E GA: o Espaço Geográfico em Análise, v. 29, p. 7-23, 2013.

SUGA, M.; KRÜGER, E.L. Recommendations of Height Restrictions for Urban Canyons in Curitiba, Brazil. Journal of Asian Architecture and Building Engineering (Online), v. 8: p. 447-452, 2009.

SZOKOLAY, S. V. Arquitectura Solar: Realización y Proyectos a Escala Mundial. Editorial Blume. Barcelona, 1983.

TURNER, D. B. Workbook of atmospheric dispersion estimates. Office of Air Program Pub. No. AP-26, Environmental Protection Agency, USA, 1970.

UNITED NATIONS, DEPARTMENT OF ECONOMIC AND SOCIALAFFAIRS, Population Division. World Urbanization Prospects: The 2011 Revision, CD-ROM Edition, 2012. 